\title{
Multiple primary malignancies involving primary sporadic colorectal cancer in Japan: incidence of gastric cancer with colorectal cancer patients may be higher than previously recognized
}

Takaharu Kato ${ }^{1 *}$, Koichi Suzuki ${ }^{1}$, Yuta Muto ${ }^{1}$, Junichi Sasaki ${ }^{1}$, Shingo Tsujinaka', Yutaka J Kawamura ${ }^{2}$, Hiroshi Noda', Hisanaga Horie ${ }^{1}$, Fumio Konishi ${ }^{3}$ and Toshiki Rikiyama' ${ }^{1}$

\begin{abstract}
Background: Improvement in the prognosis of colorectal cancer (CRC) patients has led to increasing occurrences of multiple primary malignancies (MPMs) alongside CRC but little is known about their characteristics. This study was undertaken to clarify the clinical and pathological features of MPMs, especially those at extra colonic sites, in patients with CRC.

Methods: We reviewed 1,111 patients who underwent operations for primary sporadic CRC in Saitama Medical Center, Jichi Medical University between April 2007 and March 2012. Two patients with familial adenomatous polyposis, one with hereditary non-polyposis colorectal cancer, two with colitic cancer, and any patients with metastasis from CRC were excluded. We compared the clinicopathological features of CRC patients with and without MPMs.

As a control, we used a database compiled of patients with gastric cancer (GC) detected by mass screening performed in the Saitama Prefecture in Japan 2010 and compared these with CRC patients with synchronous GC.

Results: Multiple primary malignancies at extracolonic sites were identified in 117 of 1,111 CRC patients (10.5\%). The median age was 68 (range, 29 to 96) versus 71 (50 to 92) ( $P<0.001)$. The incidence of GC (44.4\% (52 of 117)) was the highest of all MPMs. All CRC patients with GC were older than 57 years. Synchronous GC was detected in 26 patients. By contrast, out of 200,007 screened people, 225 people were diagnosed as having GC in the Saitama Prefecture. The age-standardized incidence of synchronous GC in CRC patients was significantly higher (0.53\%) than in the control group (0.03\%) (odds ratio, 18.8; 95\% confidence interval, 18.6 to 19.0; $P<0.001$ ).
\end{abstract}

Conclusion: Patients with CRC who were older than 50 years preferentially developed GC synchronously and metachronously. Thus, this patient group should undergo careful perioperative screening for GC.

Keywords: Colorectal cancer, Gastric cancer, Multiple primary malignancies

\section{Background}

Colorectal cancer $(\mathrm{CRC})$ is a common form of cancer in developed countries, being the second and third leading cause of cancer death in men and women, respectively [1], and has become an important issue in Asian countries [2,3]. Reports from the World Health Organization show that the incidence of $\mathrm{CRC}$ is rapidly rising in Asian

\footnotetext{
* Correspondence: tkato@jichi.ac.jp

'Department of Surgery, Saitama Medical Center, Jichi Medical University,

1-847 Amanuma-cho, Omiya-ku, Saitama 330-8503, Japan

Full list of author information is available at the end of the article
}

countries $[2,4,5]$, which have experienced a two- to fourfold increase in the incidence of CRC during the last few decades [6]. Patients with CRC also frequently develop multiple primary malignancies (MPMs) $[7,8]$. The prognosis for CRC patients has steadily improved, owing to both increased detection of early CRC and development of new chemotherapeutic agents. The improvement in the prognosis for CRC patients has led to an increased incidence of MPMs [9]. It is important to understand the characteristics of MPMs, in order to administer appropriate treatment and to determine suitable follow-up

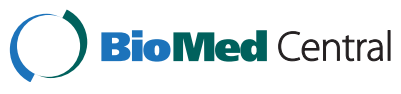

(c) 2015 Kato et al.; licensee BioMed Central. This is an Open Access article distributed under the terms of the Creative Commons Attribution License (http://creativecommons.org/licenses/by/4.0), which permits unrestricted use, distribution, and reproduction in any medium, provided the original work is properly credited. The Creative Commons Public Domain Dedication waiver (http://creativecommons.org/publicdomain/zero/1.0/) applies to the data made available in this article, unless otherwise stated. 
plans in CRC patients. This study was undertaken to review the clinical and pathological features of MPMs, especially those of extracolonic sites, in CRC patients.

\section{Methods}

Between April 2007 and March 2012, 1,111 patients underwent surgery for primary sporadic CRC in Saitama Medical Center, Jichi Medical University. From our database of CRC patients, we extracted details of patients who had developed at least one MPM in an extracolonic site while having synchronous or metachronous CRC. Synchronous MPMs were defined as malignancies detected within 6-month interval before and after the detection of CRC $[9,10]$.

All the MPMs were pathologically or cytologically confirmed as malignancies. Any metastasis to extracolonic sites from the CRC was excluded.

Two patients with familiar adenomatous polyposis, one with hereditary non-polyposis colorectal cancer, and two with ulcerative colitis associated colorectal cancer were also excluded. The tumor locations of CRC were divided into two groups: colon and rectum (portions below the level of the sacral promontory) [11]. We reviewed clinicopathological parameters, such as age, sex, location of tumor, differentiation of tumor, stage according to the tumor, node, and metastasis (TNM) classification, of the American Joint Committee on Cancer (6th edition) [12], and occurrence of MPMs at extracolonic sites.

It is not known whether the incidence of gastric cancer (GC) is higher or not in CRC patients. We performed gastroscopy for CRC patients as screening because the incidence of GC is high in Japan [13]; if GC was discovered in CRC patients before surgery, we could treat them by simultaneous operation. Of 1,111 patients, 832 underwent gastroscopy. These features in patients with CRC harboring simultaneous GC were compared with those in patients with GC that was detected by mass screening. Screening for GC is widely spread in Japan, a nation afflicted by high GC mortality [14]. In 1983, a national law was enacted that stipulated that each municipality should provide annual GC screening for inhabitants aged 40 or older, by either gastroscopy or barium meal. In 2010, 200,007 residents (6.0\% of the target population) participated in this mass screening in the Saitama Prefecture and GC was detected in 225 patients $(0.01 \%)$.

\section{Statistical analysis}

Clinical and pathological factors related to the presence of MPMs were compared by the Mann-Whitney $U$ test and the $X^{2}$ test. To enable the incidence of synchronous $\mathrm{GC}$ in patients with CRC to be compared, allowing for the differences in age distributions between patients with $\mathrm{CRC}$ and people who underwent screening for stomach abnormalities, as described, an age-adjusted odds ratio was calculated, comparing the rate in patients with synchronous GC with that in patients whose GC was diagnosed after screening. Statistical significance was indicated for $P<0.05$.

The odds ratio was presented with $95 \%$ confidence intervals. SPSS version 17 (IBM, Tokyo, Japan) was used for statistical analyses.

In this study retrospective anonymized clinical information from patients from the Saitama Medical Center, Jichi Medical University were employed. The study has been approved by the Research Ethics Committee at Jichi Medical University.

\section{Results and discussion}

Among the 1,111 patients with primary CRC, there were 117 patients (10.5\%) with MPMs. Table 1 shows the clinicopathological relationship between CRC patients with and without MPMs. Patients with CRC and MPMs were older than patients without MPMs $(P<0.001)$. All patients with CRC and MPMs were 50 years old or older.

There were no statistical differences between sexes, tumor location, or differentiation of tumor. Early CRC tended to be more associated with MPMs than advanced CRC $(P=0.034)$ (Table 1 and Figure 1). Nine patients had triple primary malignancies.

Table 2 shows the sites of the MPMs. Of 18 organs noted to have MPMs in this study, malignancies in the stomach were most frequently associated with CRC, both synchronously and metachronously, followed by lung or breast cancer.

Patients with CRC and synchronous GCs were compared with GC patients detected by mass screening carried out in the Saitama Prefecture in 2010 (Tables 3 and 4). The incidence of synchronous GC in patients with CRC was significantly higher than that of GC in the massscreened group: $2.34 \%$ versus $0.11 \%$ (Table 3 and Figure 2). The age-adjusted odds ratio for incidence of GC in the mass-screened group was 18.8 (95\% confidence interval, 18.6 to $19 ; P<0.001$ ) (Tables 3 and 4 and Figure 2). All patients with CRC with synchronous GC were 55 years old or older. The age distribution of all CRC patients peaked in the 70s. Conversely, that of CRC patients with synchronous GCs formed two peaks; one for individuals in their 60 s and one for individuals who were 80 years old or older (Figure 3).

This study demonstrates that patients with CRC are likely to develop MPMs in extracolonic sites, the occurrence of which accounted for $10.5 \%(117 / 1,111)$ in our analyses. This result is congruent with previous reports showing the occurrence of MPMs in extracolonic sites among CRC patients, which ranged from $2.4 \%$ to $17 \%$ [14-17]. Moreover, our data suggest that patients with 
Table 1 Comparison of clinical and pathological features between colorectal cancer patients with and without multiple primary malignancies

\begin{tabular}{|c|c|c|c|}
\hline & $\begin{array}{l}\text { Colorectal cancer without multiple } \\
\text { primary malignancies } \\
(n=994: 89.5 \%)\end{array}$ & $\begin{array}{l}\text { Colorectal cancer with multiple } \\
\text { primary malignancies } \\
(n=117: 10.5 \%)\end{array}$ & $P^{a}$ \\
\hline Age (years): ${ }^{b}$ & 68 (29 to 96) & 71 (50 to 92) & $<0.001^{c}$ \\
\hline$<50$ & $79(100)$ & $0(0)$ & 0.002 \\
\hline$\geq 50$ & $915(88.7)$ & $117(11.3)$ & \\
\hline Sex: & & & 0.26 \\
\hline Male & $627(88.7)$ & $80(11.3)$ & \\
\hline Female & $367(90.8)$ & $37(9.2)$ & \\
\hline Tumor location: & & & 0.345 \\
\hline Colon & $778(89.0)$ & 96 (11.0) & \\
\hline Rectum & $216(91.1)$ & $21(8.9)$ & \\
\hline Differentiation: & & & 0.678 \\
\hline Well or moderate & $981(89.4)$ & $116(10.6)$ & \\
\hline Poor & $13(92.9)$ & $1(7.1)$ & \\
\hline TNM stage: & & & 0.036 \\
\hline I & $247(87.0)$ & $37(13.0)$ & \\
\hline$\|$ & 333 (87.6) & $47(12.4)$ & \\
\hline III & 295 (91.9) & $26(8.1)$ & \\
\hline IV & $119(94.4)$ & $7(5.6)$ & \\
\hline
\end{tabular}

${ }^{a} X^{2}$ test, except as marked; ${ }^{b}$ median values (range); ${ }^{c}$ Mann-Whitney $U$ test.

Values in parentheses are percentages unless indicated otherwise.

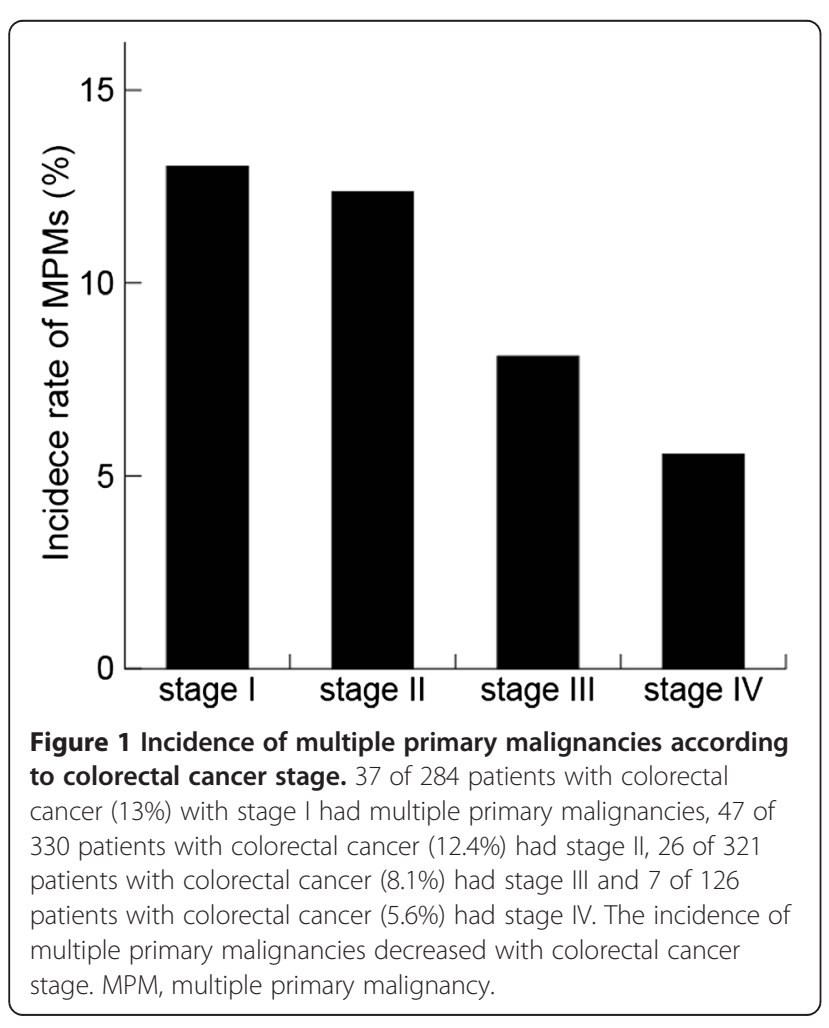

early-stage CRC are more likely to exhibit MPMs than those with advanced stages of CRC; this might be because the prognosis in early CRC patients is favorable, and thus the follow-up time becomes longer than that for advanced CRC patients. Therefore, the MPMs might occur more often in patients with early-stage CRC than in those with advanced CRC.

Our data showed that GC was the most frequently associated cancer in patients with CRC both synchronously and metachronously, consistent with previous reports $[9,10,15-19]$.

Note that increased surveillance for GC might appear to increase its incidence as a result of increased detection. Patients with CRC do seem to undergo far more testing than the general population, including gastroscopy and computed tomography, accounting for the high detection rate of GC in patients with CRC [20]. As we have mentioned before, annual GC screening for inhabitants was undertaken not only by gastroscopy but also by barium meal. In some areas of the Saitama Prefecture, individuals can choose between barium meal and gastroscopy for the screening of GC. Out of 200,007 screened people, 56,036 people $(28.0 \%)$ underwent gastroscopy in 2010. We should agree on the difficulty of comparison between the incidence of synchronous GC and that of screendetected GC. In addition, 2 of 52 patients with GC were diagnosed with stomach cancer first. After that, 
Table 2 Extracolonic site distribution of multiple primary malignancies in patients with colorectal cancer

\begin{tabular}{|c|c|c|c|c|}
\hline Organ & Total & Percentage & $\begin{array}{l}\text { Number of synchronous patients with } \\
\text { multiple primary malignancies }\end{array}$ & $\begin{array}{l}\text { Number of metachronous patients } \\
\text { with multiple primary malignancies }\end{array}$ \\
\hline Stomach & 52 & 39.4 & 26 & 26 \\
\hline Lung & 17 & 12.9 & 7 & 10 \\
\hline Breast & 10 & 7.58 & 0 & 10 \\
\hline Kidney & 8 & 6.06 & 2 & 6 \\
\hline Esophagus & 7 & 5.3 & 5 & 2 \\
\hline Prostate & 7 & 5.3 & 2 & 5 \\
\hline Bladder & 5 & 3.79 & 1 & 4 \\
\hline Thyroid & 4 & 3.03 & 0 & 4 \\
\hline Hematologic & 4 & 3.03 & 1 & 3 \\
\hline Uterus & 3 & 2.27 & 1 & 2 \\
\hline Liver & 2 & 1.52 & 1 & 1 \\
\hline Bile duct & 2 & 1.52 & 1 & 1 \\
\hline Ovary & 2 & 1.52 & 0 & 2 \\
\hline Tongue & 1 & 0.76 & 0 & 1 \\
\hline Laryngeal & 1 & 0.76 & 1 & 0 \\
\hline Anal fistula & 1 & 0.76 & 1 & 0 \\
\hline Penis & 1 & 0.76 & 0 & 1 \\
\hline Skin & 1 & 0.76 & 0 & 1 \\
\hline Total & 128 & 100 & 49 & 79 \\
\hline
\end{tabular}

the two patients were diagnosed with CRC by screening colonoscopy. So, the present study has some selection bias, increasing the incidence of GC with CRC. Consequently, it is hard to determine precisely the real magnitude of the correlation between CRC and GC. There are few reports of MPMs in CRC patients with comparative data $[10,17]$, and even then, the existing data were calculated from a population that included unscreened people; hence, it is far from accurate. After calculation of prevalence using populations that consist of screened subjects, we should employ this as comparative data. Allowing for this point, we used a database of patients with GC that was detected by screening carried out in the Saitama Prefecture in
Japan in 2010 as comparative data, to highlight a characteristic of synchronous GC with CRC. Some researchers reported that screend groups were likely to differ from unscreened groups in certain characteristics, such as familial history, diet, or smoking habits [21]. Though we could not dispute this bias, we viewed the GC data from screened individuals as a preferable comparison because the population included many unscreened people. From these results, the prevalence of synchronous GC in patients with CRC (2.6\%) was found to be extremely high, which implies that patients with CRC are at increased risk of synchronous GC. In addition, all patients with CRC who had synchronous GC were older than 50 years. Based on these data,

Table 3 Comparison of clinical features between synchronous gastric cancer with colorectal cancer patients and gastric cancer among screened group

\begin{tabular}{llll}
\hline & $\begin{array}{l}\text { Colorectal cancer patients with } \\
\text { synchronous gastric cancer } \\
(\boldsymbol{n}=\mathbf{2 6 / 1 , 1 1 1 )}\end{array}$ & $\begin{array}{l}\text { Gastric cancer among } \\
\text { screened group } \\
(\boldsymbol{n}=\mathbf{2 2 5 / 2 0 0 , 0 0 7 )}\end{array}$ & $\boldsymbol{P}^{\mathbf{a}}$ \\
\hline Age (years) & $69(58-87)$ & $71(42-95)$ & $0.600^{\mathrm{b}}$ \\
Sex: & $20(76.9)$ & $164(72.9)$ & 0.66 \\
Male & $6(23.1)$ & $61(27.1)$ & 0.11 \\
Female & 2.34 & $0.001^{\mathrm{c}}$ \\
\hline Incidence & &
\end{tabular}

${ }^{\mathrm{a}} \chi^{2}$ test, except as marked; ${ }^{\mathrm{b}}$ Mann-Whitney $U$ test; ${ }^{\mathrm{c}}$ age-adjusted. 
Table 4 Comparison of the incidence of gastric cancer between colorectal cancer patients and screened patients

\begin{tabular}{|c|c|c|c|c|c|}
\hline \multirow[b]{2}{*}{$\begin{array}{l}\text { Age } \\
\text { (years) }\end{array}$} & \multicolumn{2}{|c|}{$\begin{array}{l}\text { Synchronous } \\
\text { gastric cancer } \\
\text { patients }\end{array}$} & \multicolumn{2}{|c|}{$\begin{array}{l}\text { Gastric cancer } \\
\text { patients among } \\
\text { screened group }\end{array}$} & \multirow{2}{*}{$\begin{array}{l}\text { Odds ratio for } \\
\text { gastric cancer } \\
\text { among screened } \\
\text { group }\end{array}$} \\
\hline & $\begin{array}{l}\text { Gastric } \\
\text { cancer }\end{array}$ & $\begin{array}{l}\text { All } \\
\text { colorectal } \\
\text { cancer }\end{array}$ & $\begin{array}{l}\text { Gastric } \\
\text { cancer }\end{array}$ & $\begin{array}{l}\text { All } \\
\text { screened } \\
\text { people }\end{array}$ & \\
\hline$<40$ & 0 & 22 & 0 & 4,138 & Invalid value \\
\hline 40 to 44 & 0 & 28 & 1 & 12,659 & Invalid value \\
\hline 45 to 49 & 0 & 29 & 3 & 11,515 & Invalid value \\
\hline 50 to 54 & 0 & 52 & 3 & 11,729 & Invalid value \\
\hline 55 to 59 & 1 & 110 & 9 & 16,087 & $16.37(2.06,130.48)$ \\
\hline 60 to 64 & 7 & 152 & 26 & 34,902 & $64.76(27.67,151.57)$ \\
\hline 65 to 69 & 6 & 198 & 56 & 42,917 & $23.92(10.18,56.17)$ \\
\hline 70 to 74 & 3 & 211 & 62 & 35,615 & $8.41(2.62,2701)$ \\
\hline 75 to 79 & 3 & 152 & 80 & 20,515 & $10.31(3.15,33.68)$ \\
\hline$\geq 80$ & 6 & 157 & 26 & 9,930 & $15.14(6.14,37.31)$ \\
\hline All ages & 26 & 1,111 & 225 & 200,007 & $18.8(18.6 \text { to } 19.0)^{\mathrm{a}}$ \\
\hline
\end{tabular}

age-adjusted.

Values in parentheses are $95 \%$ confidence intervals.

careful perioperative screening is necessary for the detection of GC in patients with sporadic CRC who are older than 50 years.

In addition to the finding that the most common site of a metachronous MPM in CRC patients is the stomach

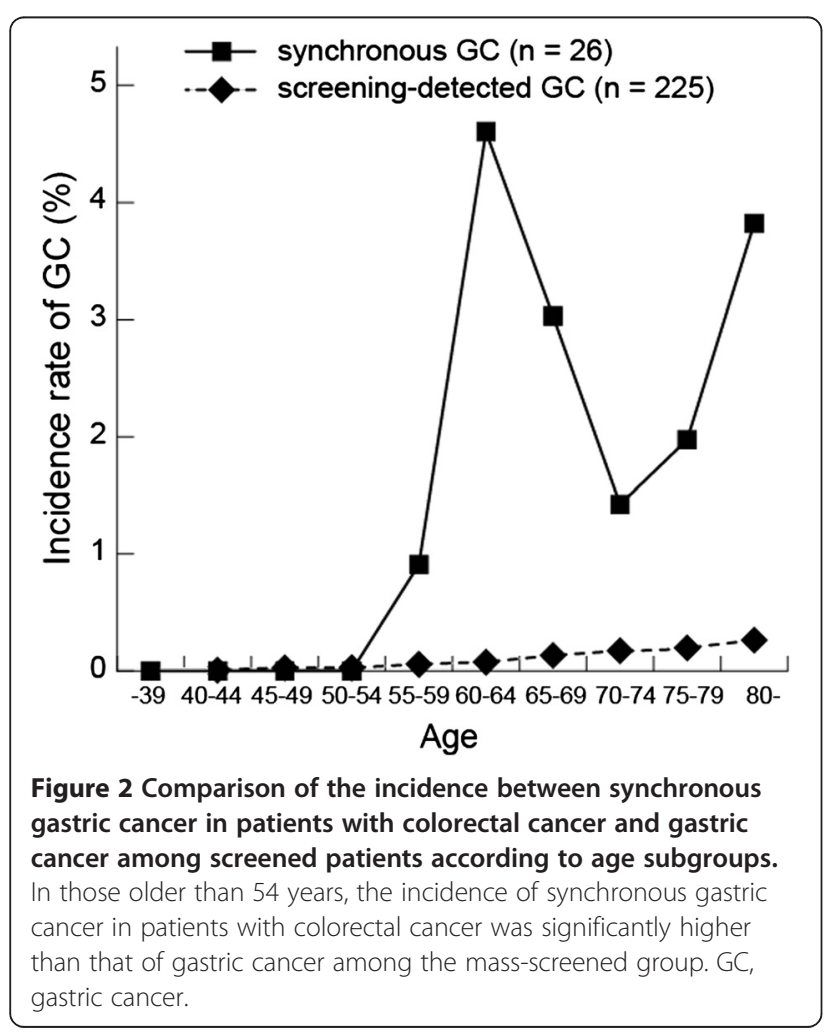

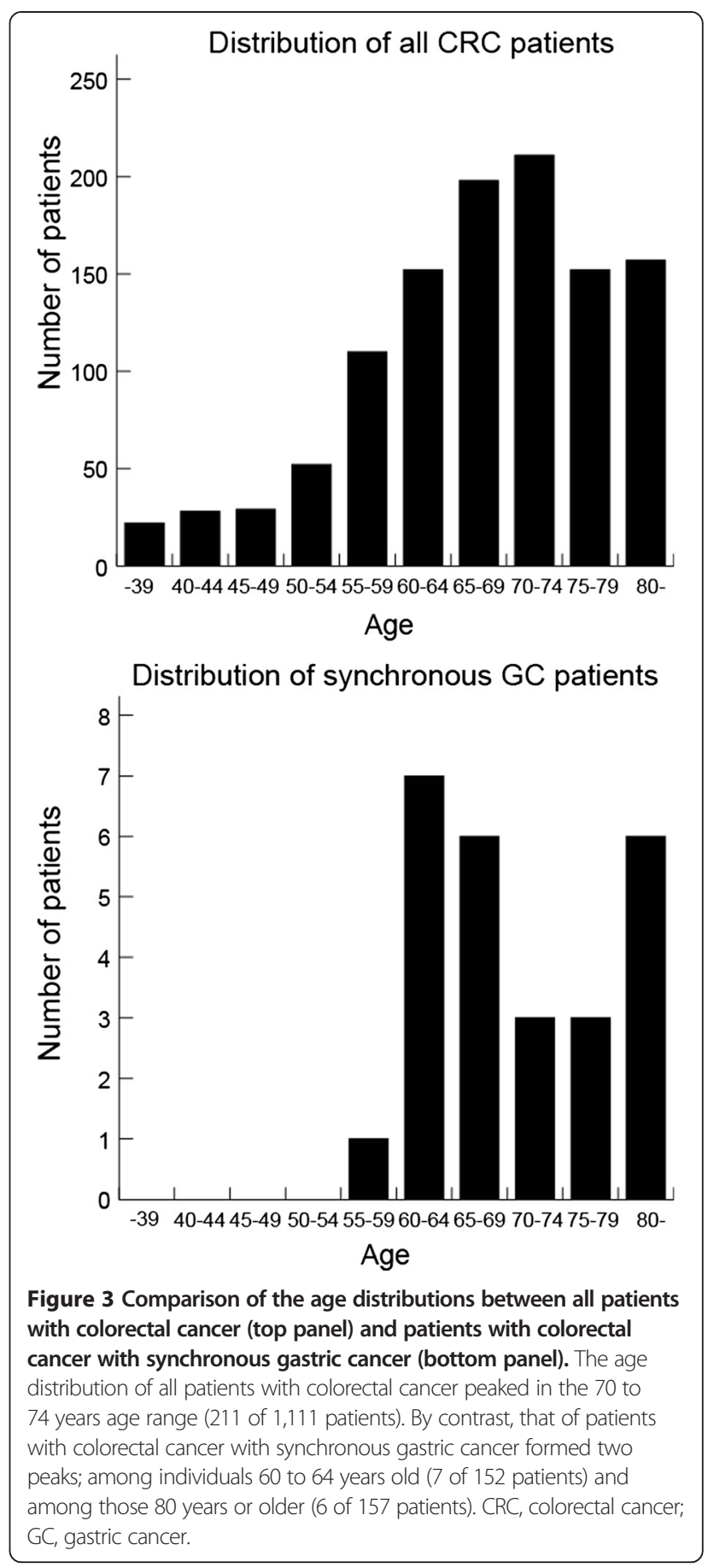

[22], one of the most common MPMs in patients with GC is CRC [23,24]. These facts seem to suggest that GC and $\mathrm{CRC}$ share the same risk factors. In a previous study, microsatellite instability [19], translocation of TP53 $[25,26]$ and ageing $[22,27,28]$ were regarded as shared risk factors between GC and CRC. In terms of ageing, the median age of CRC patients with MPMs was significantly higher than that of CRC patients without MPMs, which agrees with those reports. Intriguingly, 
the age distribution of CRC patients with synchronous GC formed two characteristic peaks; not only was there a peak at 80 years old or older, but there was also a peak for people in their 60s. Familiar adenomatous polyposis or hereditary non-polyposis colorectal cancer are given as hereditary diseases to be complicated with GC and CRC. We excluded patients with these diseases from our cohort of patients with CRC by checking patients' familial histories. Additionally, in hereditary non-polyposis colorectal cancer, the mean age at diagnosis as CRC is 42 to 50.4 years $[29,30]$. In familiar adenomatous polyposis, without surgical intervention, patients almost inevitably develop CRC by a mean age of 40 or 50 years [31]. We concluded that these hereditary diseases were less likely to be included. It is thought that there are some factors that are not due to ageing or known hereditary disease.

In the 18 organs that had MPMs, the lung was the second most frequently associated with CRC, followed by the stomach, and then the breast. In Japan, the organ with the highest incidence of MPMs in Japan is the stomach, followed by the colon and rectum, and then the lung and breast [13]. This sequence matches precisely with that of MPMs in our cohort of patients with CRC.

There are some limitations to this study. First, this research was performed retrospectively. Second, our data did not include information regarding Helicobacter pylori infection status. It is believed that 70 to $80 \%$ of people over 40 years of age in Japan are infected with $H$. pylori [32]. H. pylori infection is an important factor that has been associated with the development of GC [33]. The incidence of $H$. pylori infection of the stomach in European countries is less than that in Japan [34]. In a European study of MPMs with CRC, cancer in the stomach is far from frequent [35]. In this study, H. pylori might contribute to the high incidence of GC with CRC.

Finally, our data did not include any information regarding atrophic gastritis; a previous study revealed that atrophic gastritis might be a major cause of GC [36]. For these reasons, additional studies are required for further evaluation.

\section{Conclusions}

Gastric cancer was the most common synchronous or metachronous MPM in patients with CRC. Careful perioperative screening is necessary for the detection of MPMs in patients with CRC. However, screening for $\mathrm{GC}$ is not always necessary in sporadic CRC patients younger than 50 years.

\footnotetext{
Abbreviations

CRC: colorectal cancer; GC: gastric cancer; MPM: multiple primary malignancy; TNM: tumor, node, and metastasis.
}

\section{Competing interests}

The authors declare that they have no competing interests.

\section{Authors' contributions}

TK participated in designing the study, performed the statistical analysis and wrote the manuscript. KS participated in designing the study. YM, JS, ST, YJK, $\mathrm{HN}$, and $\mathrm{HH}$ participated in the acquisition of data. FK and TR conceived the study and participated in its design and coordination. All authors read and approved the final manuscript.

\section{Acknowledgement}

The authors thank Saitama Prefecture for providing the data on the screening of gastric cancer.

\section{Author details}

'Department of Surgery, Saitama Medical Center, Jichi Medical University, 1-847 Amanuma-cho, Omiya-ku, Saitama 330-8503, Japan. ${ }^{2}$ Tsudanuma Central General Hospital, 1-9-17 Yatsu, Narashino-shi, Chiba 275-0026, Japan. ${ }^{3}$ Nerima Hikarigaoka Hospital, 2-11-1 Hikarigaoka, Nerima-ku, Tokyo 179-0072, Japan.

Received: 3 November 2014 Accepted: 24 December 2014 Published online: 07 February 2015

\section{References}

1. Jemal A, Bray F, Center MM, Ferlay J, Ward E, Forman D (2011) Global cancer statistics. CA Cancer J Clin 61:69-90

2. Yiu HY, Whittemore AS, Shibata A (2004) Increasing colorectal cancer incidence rates in Japan. Int J Cancer 109:777-81

3. Yee YK, Tan VP, Chan P, Hung IF, Pang R, Wong BC (2009) Epidemiology of colorectal cancer in Asia. J Gastroenterol Hepatol 24:1810-6

4. Lu JB, Sun XB, Dai DX, Zhu SK, Chang QL, Liu SZ et al. (2003) Epidemiology of gastroenterologic cancer in Henan Province. China World J Gastroenterol 9:2400-3

5. Yang L, Parkin DM, Li LD, Chen YD, Bray F (2004) Estimation and projection of the national profile of cancer mortality in China: 1991-2005. Br J Cancer 90:2157-66

6. Sung JJ, Lau JY, Goh KL, Leung WK (2005) Increasing incidence of colorectal cancer in Asia: implications for screening. Lancet Oncol 6:871-6

7. Kobayashi Y, Arimoto H, Watanabe S (1991) Occurrence of multiple primary cancer at the National Cancer Center Hospital, 1962-1989. Jpn J Clin Oncol 21:233-51

8. Tsukuma H, Fujimoto I, Hanai A, Hiyama T, Kitagawa T, Kinoshita N (1994) Incidence of second primary cancers in Osaka residents, Japan, with special reference to cumulative and relative risks. Jpn J Cancer Res 85:339-45

9. Lee WS, Lee JN, Choi S, Jung M, Baek JH, Lee WK (2010) Multiple primary malignancies involving colorectal cancer-clinical characteristics and prognosis with reference to surveillance. Langenbecks Arch Surg 395:359-64

10. Lee SH, Ahn BK, Baek SU (2009) Multiple primary cancers in extracolonic sites with colorectal cancer. Int J Color Dis 24:301-4

11. Oya M, Takahashi S, Okuyama T, Yamaguchi M, Ueda Y (2003) Synchronous colorectal carcinoma: clinico-pathological features and prognosis. Jpn J Clin Oncol 33:38-43

12. Greene F, Page D, Fleming I, Fritz A, Balch C, Haller D et al. (2002) AJCC Cancer Staging Manual, 6th edn. Springer, New York

13. Matsuda A, Matsuda T, Shibata A, Katanoda K, Sobue T, Nishimoto H (2013) Cancer incidence and incidence rates in Japan in 2007: a study of 21 population-based cancer registries for the Monitoring of Cancer Incidence in Japan (MCIJ) project. Jpn J Clin Oncol 43:328-36

14. Hisamichi S (1989) Screening for gastric cancer. World J Surg 13:31-7

15. Maruyama H, Hasuike Y, Furukawa J, Naoi M, Takata N, Yayoi E et al. (1992) Multiple colorectal carcinomas and colorectal carcinoma associated with extracolonic malignancies. Surg Today 22:99-104

16. Ueno M, Muto T, Oya M, Ota H, Azekura K, Yamaguchi T (2003) Multiple primary cancer: an experience at the Cancer Institute Hospital with special reference to colorectal cancer. Int J Clin Oncol 8:162-7

17. Yamamoto S, Yoshimura K, Ri S, Fujita S, Akasu T, Moriya Y (2006) The risk of multiple primary malignancies with colorectal carcinoma. Dis Colon Rectum 49:S30-6 
18. Lim SB, Jeong SY, Choi HS, Sohn DK, Hong CW, Jung KH et al. (2008) Synchronous gastric cancer in primary sporadic colorectal cancer patients in Korea. Int J Color Dis 23:61-5

19. Yun HR, Yi L, Cho YK, Park JH, Cho YB, Yun SH et al. (2009) Double primary malignancy in colorectal cancer patients - MSI is the useful marker for predicting double primary tumors. Int J Color Dis 24:369-75

20. Yoon SN, Oh ST, Lim SB, Kim TW, Kim JH, Yu CS et al. (2010) Clinicopathologic characteristics of colorectal cancer patients with synchronous and metachronous gastric cancer. World J Surg 34:2168-76

21. Mizoue T, Yoshimura T, Tokui N, Hoshiyama Y, Yatsuya H, Sakata K et al. (2003) Prospective study of screening for stomach cancer in Japan. Int J Cancer 106:103-7

22. Schatzkin A, Baranovsky A, Kessler LG (1988) Diet and cancer. Evidence from associations of multiple primary cancers in the SEER program. Cancer 62:1451-7

23. Ha TK, An JY, Youn HG, Noh JH, Sohn TS, Kim S (2007) Surgical outcome of synchronous second primary cancer in patients with gastric cancer. Yonsei Med J 48:981-7

24. Eom BW, Lee HJ, Yoo MW, Cho JJ, Kim WH, Yang HK et al. (2008) Synchronous and metachronous cancers in patients with gastric cancer. J Surg Oncol 98:106-10

25. Uchino S, Noguchi M, Ochiai A, Saito T, Kobayashi M, Hirohashi S (1993) p53 mutation in gastric cancer: a genetic model for carcinogenesis is common to gastric and colorectal cancer. Int J Cancer 54:759-64

26. Sawai T, Nanashima A, Tsuji T, Yamaguchi H, Yasutake T, Nakagoe T et al. (2001) Instability of chromosome 17 and the p53 locus in non-familia colorectal cancer with multiple primary malignancies. J Exp Clin Cancer Res 20:401-5

27. Wynder EL, Mushinski MH, Spivak JC (1977) Tobacco and alcohol consumption in relation to the development of multiple primary cancers. Cancer 40:1872-8

28. Saito S, Hosoya Y, Togashi K, Kurashina K, Haruta H, Hyodo M et al. (2008) Prevalence of synchronous colorectal neoplasms detected by colonoscopy in patients with gastric cancer. Surg Today 38:20-5

29. Hampel H, Frankel WL, Martin E, Arnold M, Khanduja K, Kuebler P et al. (2005) Screening for the Lynch syndrome (hereditary nonpolyposis colorectal cancer). N Engl J Med 352:1851-60

30. Stoffel E, Mukherjee B, Raymond VM, Tayob N, Kastrinos F, Sparr J et al (2009) Calculation of risk of colorectal and endometrial cancer among patients with Lynch syndrome. Gastroenterology 137:1621-7

31. Vasen HF, Moslein G, Alonso A, Aretz S, Bernstein I, Bertario L et al. (2008) Guidelines for the clinical management of familial adenomatous polyposis (FAP). Gut 57:704-13

32. Asaka M, Kimura T, Kudo M, Takeda H, Mitani S, Miyazaki T et al. (1992) Relationship of Helicobacter pylori to serum pepsinogens in an asymptomatic Japanese population. Gastroenterology 102:760-6

33. The EUROGAST Study Group (1993) An international association between Helicobacter pylori infection and gastric cancer. Lancet 341:1359-62

34. Graham DY, Adam E, Klein PD, Evans DJ Jr, Evans DG, Hazell SL et al. (1989) Epidemiology of Campylobacter pylori infection. Gastroenterol Clin Biol 13:84B-8

35. Evans HS, Moller H, Robinson D, Lewis CM, Bell CM, Hodgson SV (2002) The risk of subsequent primary cancers after colorectal cancer in southeast England. Gut 50:647-52

36. Derakhshan MH, Malekzadeh R, Watabe H, Yazdanbod A, Fyfe V, Kazemi A et al. (2008) Combination of gastric atrophy, reflux symptoms and histological subtype indicates two distinct aetiologies of gastric cardia cancer. Gut 57:298-305

\section{Submit your next manuscript to BioMed Central and take full advantage of:}

- Convenient online submission

- Thorough peer review

- No space constraints or color figure charges

- Immediate publication on acceptance

- Inclusion in PubMed, CAS, Scopus and Google Scholar

- Research which is freely available for redistribution 